\title{
Low-Grade Esthesioneuroblastoma Presenting as SIADH: A Review of Atypical Manifestations
}

\author{
Andrew Senchak, ${ }^{1}$ Judy Freeman, ${ }^{2}$ Douglas Ruhl, ${ }^{3}$ Jordan Senchak, ${ }^{4}$ and Christopher Klem ${ }^{3}$ \\ ${ }^{1}$ Department of Otolaryngology, Walter Reed National Military Medical Center, 8901 Wisconsin Avenue Bethesda, \\ MD 20889-5600, USA \\ ${ }^{2}$ Department of Pathology, Tripler Army Medical Center, Honolulu, HI 96859 5000, USA \\ ${ }^{3}$ Department of Otolaryngology, Tripler Army Medical Center, Tripler AMC, Honolulu, HI 96859 5000, USA \\ ${ }^{4}$ Grove City College, Grove City, PA 16127, USA
}

Correspondence should be addressed to Andrew Senchak, andrew.senchak@us.army.mil

Received 17 October 2012; Accepted 8 November 2012

Academic Editors: J. I. De Diego, M. T. Kalcioglu, K. Morshed, C.-S. Rhee, and G. Zhou

Copyright ( 12012 Andrew Senchak et al. This is an open access article distributed under the Creative Commons Attribution License, which permits unrestricted use, distribution, and reproduction in any medium, provided the original work is properly cited.

\begin{abstract}
Esthesioneuroblastoma (ENB) is a neuroendocrine tumor that typically manifests as advanced stage malignancy in the superior nasal cavity. The hallmark symptoms include nasal obstruction and epistaxis, which result from local tissue invasion. Atypical clinical features can also arise and must be considered when diagnosing and treating ENB. These can include origin in an ectopic location, unusual presenting symptoms, and associated paraneoplastic syndromes. The case described here reports a nasal cavity ENB with atypical clinical features that occurred in a young female. Her tumor was low grade, appeared to arise primarily from the middle nasal cavity, and presented as syndrome of inappropriate antidiuretic hormone (SIADH). She also became pregnant shortly after diagnosis, which had implications on her surgical management. We review the atypical features that uncommonly occur with ENB and the clinical considerations that arise from these unusual characteristics.
\end{abstract}

\section{Introduction}

Esthesioneuroblastoma is a rare nasal malignancy that accounts for $3 \%$ of all intranasal tumors [1]. A review of the world literature revealed up to 1000 published cases and suggested that the true incidence may be underestimated [2]. ENBs have a bimodal age of onset in the second and sixth decades of life and most commonly manifest as aggressive tumors in the superior aspect of the nasal cavity in close proximity to the cribriform plate [3]. The typical symptoms include unilateral nasal obstruction and epistaxis which present in later stages of disease, as early lesions are usually slow growing and asymptomatic [4].

ENBs arise from cells of neuroectodermal origin. In the nasal cavity, this type of tissue occurs in olfactory epithelium which can be found in the superior nasal cavity at the area of the cribriform plate, along the superior septum, and at the superior turbinate [5]. The pathologic features of this tumor are distinct and include nesting, low-grade stippled nuclei and neurofibrillary stroma with formation of pseudorosettes [6]. Like many malignancies, ENBs primarily cause invasion and destruction of surrounding structures, with potential for metastasis.

We describe a patient with ENB that presented in several atypical ways-low-grade tumor which appeared to originate in the middle nasal cavity, presentation as syndrome of inappropriate antidiuretic hormone (SIADH), and diagnosis during pregnancy. We review the unusual characteristics that may uncommonly occur in ENBs and which must be considered when evaluating patients with this malignancy.

\section{Case}

A 28-year-old female presented with recurrent episodes of emesis, malaise, and diarrhea over a 3-year time period, from 2004 to 2007. She was admitted twice for hyponatremia, 


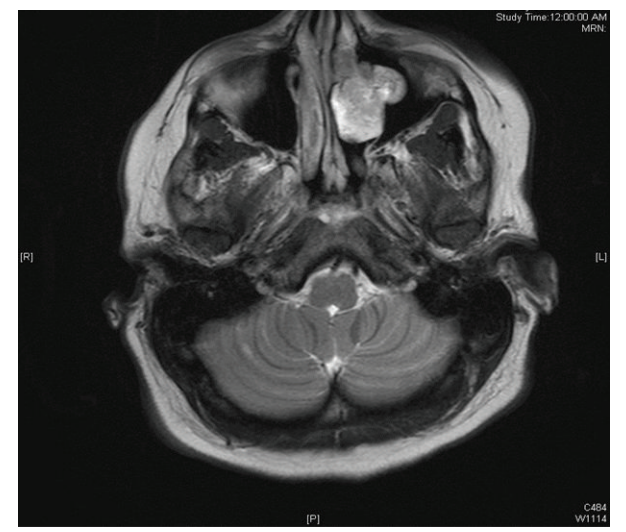

Figure 1: T2 weighted MRI with gadolinium showing enhancing mass in left lateral nasal wall and maxillary sinus.

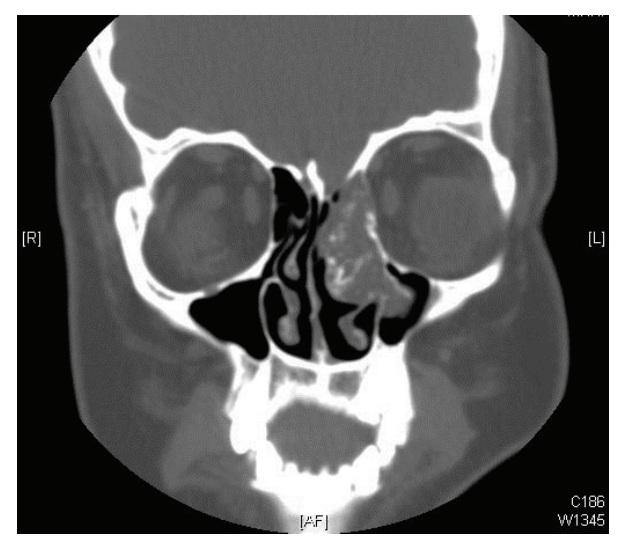

Figure 2: CT sinus demonstrating indolent mass with stippled calcifications centered at left middle turbinate.

with a nadir serum sodium of $114 \mathrm{mEq} / \mathrm{L}$. Her sodium levels normalized each time with saline administration, and so her hyponatremia was believed to be secondary to gastroenteritis and dehydration. In July 2007, she was seen again for malaise and recurrent emesis and was admitted with a sodium level at $112 \mathrm{mEq} / \mathrm{L}$. Endocrinology was consulted for further workup. Their evaluation was significant for low calcium level $(7.8 \mathrm{mg} / \mathrm{dL})$, low serum osmolality (247 mOsm/kg), low urine osmolality (419 mOsm/kg), low phosphorus level $(2.9 \mathrm{mg} / \mathrm{dL})$, and low parathyroid hormone level $(2.9 \mathrm{pg} / \mathrm{mL})$. A repeat urine osmolality was elevated $(1026 \mathrm{mOsm} / \mathrm{kg})$. The remainder of her chemistry panel, urine sodium, cortisol, and thyroid function studies were normal. The endocrinology service diagnosed her with chronic SIADH and placed her on an oral course of demeclocycline to maintain sodium levels.

2.1. Radiographic Studies. An abdominal CT scan revealed bilateral nephrolithiasis without any evidence of neoplastic processes. A brain MRI with gadolinium demonstrated a heterogeneous mass in the left nasal cavity, with high T2 and low T1 signal, with no intracranial involvement (Figure 1).

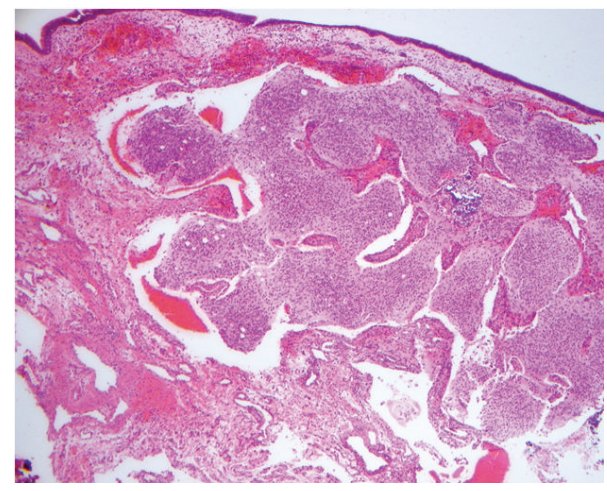

FIGURE 3: Low power view showing a nested proliferation of small hyperchromatic cells, prominent fibrillary background, focal microcalcification, and overlying respiratory epithelium.

CT scan evaluation of the sinuses showed an indolentappearing mass with stippled calcifications that was centered at the left ostiomeatal unit and middle turbinate, protruding into the left maxillary sinus, and extending superiorly toward the cribriform plate (Figure 2).

2.2. Surgical Treatment. The patient was referred to otolaryngology for evaluation of the nasal mass. Endoscopic evaluation revealed a $2 \mathrm{~cm}$ smooth-bordered, polypoid mass at the left ostiomeatal unit which extended superiorly and toward the nasal septum. Outpatient tissue biopsy of this mass was consistent with glial tissue, most likely glioma. This tumor was believed to be the underlying cause of the patient's SIADH, and surgical excision was recommended. During this time, however, the patient also discovered that she was 10 -week pregnant. In consultation with the Obstetrics department, the decision was made to perform surgical excision because of the potential risk of recurrent hyponatremia throughout the pregnancy. During second trimester, the patient underwent endoscopic total resection of the neoplasm. The tumor was noted to emanate from the lateral nasal wall and dissected easily from the underlying bone. Although it extended superiorly to the cribriform area, there was no apparent attachment to the superior nasal cavity.

2.3. Pathological Evaluation. Histologic examination of hematoxylin and eosin-stained slides demonstrated a proliferation of small, hyperchromatic cells exhibiting a predominantly nested pattern, in a background of fibrillar material with prominent dystrophic calcifications and a few pseudorosettes (Figure 3). The tumor was immunoreactive for chromogranin, glial fibrillary acid protein, pancytokeratin, neurofilament protein, neuron-specific enolase, Neu-N, S100 , and synaptophysin. The final pathology interpretation of the excised mass was consistent with grade 1 esthesioneuroblastoma with involvement of the middle turbinate remnant that was submitted as a margin. 
2.4. Followup. Following receipt of the pathology report, a wider surgical resection was recommended to the patient to ensure negative surgical margins given in the malignant diagnosis. The patient elected to wait until after delivery before proceeding with additional surgical management. In the interim, her sodium levels and osmolality normalized. Of note, her hypoparathyroidism and bilateral nephrolithiasis, which were felt to be due to repeated gastroenteritis, resolved as well. Approximately 8 months after her initial surgery, and following the uncomplicated delivery of her pregnancy, the patient underwent wider excision of the left lateral nasal cavity wall. All specimens from this second procedure were negative for residual malignancy. Her case was presented at a multidisciplinary tumor board, and the consensus opinion was that she would not require any adjuvant radiation or chemotherapy. The patient has been followed for 2 years since surgical treatment and has not demonstrated any recurrence of disease. Her sodium levels continue to be normal.

\section{Discussion}

This case highlights several atypical manifestations that can occur with esthesioneuroblastomas. First, it is rare for an ENB to originate outside the region of the superior nasal cavity, where olfactory tissue is normally located. This disease is therefore a diagnosis of exclusion in ectopic locations. Several published reports confirm ectopic cases of ENB throughout the nasal cavity and the central nervous system. These include cases with primary origin in the posterior nasal septum [5], the nasal inferior meatus [7], the maxillary sinus $[8,9]$, the pterygopalatine fossa $[10]$, the sella turcica [11], the pituitary gland [12] within the sphenoid sinus and petrous apex $[13,14]$, and in the dentoalveolar ridge [15]. Our patient had a low-grade tumor that appeared to emanate from the area of the left lateral nasal wall, although it did extend to the superior aspect of the nasal cavity. It is unknown whether ectopically located ENBs are associated with a more favorable tumor grade, and the reported cases range from low to high grade malignancies.

ENBs have also been reported to present with unusual signs and symptoms. For instance, some cases have occurred as bilateral noncontiguous tumors [16]. Some tumors invade into the orbit and can initially present with proptosis, sudden blindness, palsy of orbital cranial nerves, and ophthalmoplegia [17-20]. Compression and/or invasion of the nasolacrimal system has caused initial presentation with epiphora [21]. One case reports initial presentation as an oral cavity lesion, which resulted from direct extension from maxillary sinus involvement [8]. Psychological symptoms such as frontal lobe dysfunction and postpartum depression have been reported as presenting symptoms as well [22, 23]. Neck metastasis is known to occur in $10-30 \%$ of cases and can be the initial symptom of disease [24]. One case reports first presentation as bilateral metastatic cervical lymphadenopathy, which is very rare [17]. Since ENBs often demonstrate aggressive behavior and hematologic spread, recurrent disease can sometimes be first recognized in areas far away from the primary site. ENB metastasis most commonly occurs in lungs and bones, followed by liver, spleen, scalp, breast, adrenal gland, and ovary. Metastatic spread has also been reported in rare sites such as thoracic spine, spinal cord, parotid, and the trachea $[17,25,26]$. The heterogeneity of metastatic locations must be remembered when following a patient's clinical course even after ENB treatment.

Very rarely, ENBs present with symptoms that are associated with paraneoplastic syndromes, such as our patient. These syndromes are known to affect up to $8 \%$ of all cancer cases, most often in small cell carcinoma of the lung, breast cancer, and gynecologic and hematologic malignancies [27]. Head and neck cancers are only infrequently involved. Paraneoplastic disorders arise when tumors produce hormones, peptides, or cytokines that lead to metabolic derangements. Antidiuretic hormone $(\mathrm{ADH})$, adrenocorticotropic hormone (ACTH), calcium, and insulin represent the most common endocrine substances produced in paraneoplastic syndromes. We found 14 reports of ENB associated with production of $\mathrm{ADH}[8,28-40]$ and 8 publications reporting ACTH production [41-48]. Sharma et al. report one fatal case of advanced ENB with humoral hypercalcemia of malignancy that became refractory to therapy [49]. One report describes an ENB that produced catecholamines, which normalized after surgery [40].

Although still infrequent, $\mathrm{ACTH}$ and $\mathrm{ADH}$ are the most common paraneoplastic processes to be associated with ENB. Ectopic ACTH production leads to elevated cortisol levels which usually results in Cushing syndrome. This syndrome consists of characteristic moon facies appearance, buffalo hump, and truncal obesity and can be associated with dysfunction in the cardiovascular, endocrine, neural, gastrointestinal, integumentary, and musculoskeletal systems. It is estimated that between $8 \%$ and $18 \%$ of total Cushing syndrome cases are due to ectopic ACTH production [50]. Most of the 8 reported cases of ectopic ACTH were from primary ENB tumors. It has also been found to first appear with recurrent disease, as in one pediatric case of late cervical lymph node recurrence [41] and in two adult cases of local recurrence despite aggressive surgical management [42, 48]. Although one patient died of recurrent disease, treatment of the ENB and/or recurrence led to resolution of the associated Cushing's syndrome in all other cases.

Excess of $\mathrm{ADH}$ production leads to a different clinical presentation due to the resultant hyponatremia and hyposmolality. These patients have an associated increase in urine osmolality due to elevated urinary sodium excretion and are usually euvolemic. Inappropriately high levels of $\mathrm{ADH}$ are also seen and are typically out of proportion to the hypoosmolality [37]. Other causes such as adrenal failure and hypothyroidism must be ruled out to establish a diagnosis of SIADH. Octreotide scanning can be used to look for areas of increased uptake, that indicate locations with neuroendocrine activity. Staining for arginine vasopressin (ADH) in the tumor tissue can also be done to help support the diagnosis.

Development of SIADH does not appear to correlate with a higher cancer grade or stage in ENB cases. Two of the reported cases of SIADH occurred in low grade tumors, 
and one was mainly located around the middle turbinate, similar to our patient [37]. There have also been documented cases of SIADH that first occur in a locally recurrent tumor, without apparent paraneoplastic disease in the initial tumor [31]. Advanced stages can also be involved as one reported case occurred in a tumor that invaded into the cranial cavity [30]. One case occurred in an advanced stage ENB that transformed into a ganglioneuroma after chemoradiation therapy [32], and another one was in a mixed olfactory neuroblastoma/craniopharyngioma [34]. In all cases where tumor resection was possible, SIADH resolved after surgery, as in our patient. This strongly supports ENB as the cause of excess ADH production in these patients [27].

With most paraneoplastic processes, a diagnosis of cancer is usually made before discovery of ectopic hormone production [27]. In our patient, SIADH occurred before discovery of her tumor, and her hyponatremia was the impetus for obtaining the brain MRI. She also became pregnant during treatment, which made surgical resection more urgent. Development of hyponatremia can complicate the course of pregnancy, making treatment imperative. Initially, nausea and malaise develop from increased intracranial pressure as water migrates into cells. With increasing severity, seizures can develop with eventual coma and brainstem herniation in advanced stages [51]. Treatment with fluid restriction should be initiated, and early delivery should also be considered in cases of hyponatremia in pregnancy [52]. However, when ENB is suspected as the cause of SIADH, early discussions about the risks and benefits of surgery should be communicated between the patient, surgeon, anesthesia provider, and obstetrician. In cases where surgery is not performed, somatostatin analogues have been proposed to have a potential role in treatment, although this has not been adequately researched [37].

\section{Conclusion}

While most ENBs originate in the superior nasal vault and present with typical symptoms of nasal obstruction and epistaxis in late stages of disease, uncommon manifestations should be considered as well. ENB should be kept in the differential of masses throughout the nasal cavity, paranasal sinuses, and surrounding anatomical locations. A patient with a history of prior ENB can have recurrence in distant locations as well. Paraneoplastic processes, particularly excess $\mathrm{ACTH}$ and $\mathrm{ADH}$, should warrant radiographic workup for ENB. Unusual manifestations should be remembered in all cases of ENB, as the stage and grade of tumor do not seem to demonstrate association with atypical disease.

\section{Conflict of Interests}

The authors declare that they have no conflict of interests to report. The views expressed in this paper are those of the authors and do not reflect the official policy of the Department of the Army, the Department of Defense, or the U.S. Government. The appearance of name-brand products in this paper does not constitute endorsement by
San Antonio Military Medical Center, the U.S. Army Medical Department, the U.S. Army Office of the Surgeon General, the Department of the Army, Department of Defense, or the U.S. Government of the information, products, or services contained therein.

\section{References}

[1] C. L. Mc and H. E. Harris, "Neurogenic tumors of the nasal fossa," Journal of the American Medical Association, vol. 157, no. 4, pp. 318-321, 1955.

[2] G. Broich, A. Pagliari, and F. Ottaviani, "Esthesioneuroblastoma: a general review of the cases published since the discovery of the tumour in 1924," Anticancer Research, vol. 17, no. 4, pp. 2683-2706, 1997.

[3] E. M. Diaz, R. H. Johnigan, C. Pero et al., "Olfactory neuroblastoma: the 22-year experience at one comprehensive cancer center," Head and Neck, vol. 27, no. 2, pp. 138-149, 2005.

[4] V. J. Lund, D. Howard, W. Wei, and M. Spittle, "Olfactory neuroblastoma: past, present, and future?" Laryngoscope, vol. 113, no. 3, pp. 502-507, 2003.

[5] K. S. Cho, D. G. Lee, K. U. Choi, and H. J. Roh, "Primary olfactory neuroblastoma originating from the posterior nasal septum," Otolaryngology, vol. 142, no. 5, pp. 776-777, 2010.

[6] H. Faragalla and I. Weinreb, "Olfactory neuroblastoma: a review and update," Advances in Anatomic Pathology, vol. 16, no. 5, pp. 322-331, 2009.

[7] J. Y. Lee and H. K. Kim, "Primary olfactory neuroblastoma originating from the inferior meatus of the nasal cavity," American Journal of Otolaryngology, vol. 28, no. 3, pp. 196200, 2007.

[8] S. L. Myers, D. A. Hardy, C. B. Wiebe, and J. Shiffman, "Olfactory neuroblastoma invading the oral cavity in a patient with inappropriate antidiuretic hormone secretion," Oral Surgery, Oral Medicine, Oral Pathology, vol. 77, no. 6, pp. 645650, 1994.

[9] A. Unal, S. Ozlugedik, M. S. Tezer, S. Kulacoglu, and M. Ozcan, "An atypical esthesioneuroblastoma of the inferior nasal cavity and maxillary sinus: report of a case," Tumori, vol. 92, no. 5, pp. 440-443, 2006.

[10] V. Seccia, R. Lenzi, A. P. Casani, and L. Muscatello, "Ectopic olfactory neuroblastoma arising in the pterygopalatine fossa," Otolaryngology, vol. 142, no. 3, pp. 460-461, 2010.

[11] J. H. Lin, D. H. Tsai, and Y. H. Chiang, "A primary sellar esthesioneuroblastomas with unusual presentations: a case report and reviews of literatures," Pituitary, vol. 12, no. 1, pp. 70-75, 2009.

[12] L. Mariani, B. Schaller, J. Weis, C. Ozdoba, and R. W. Seiler, "Esthesioneuroblastoma of the pituitary gland: a clinicopathological entity? Case report and review of the literature," Journal of Neurosurgery, vol. 101, no. 6, pp. 1049-1052, 2004.

[13] G. Chacko, S. M. Chandi, and M. J. Chandy, "Primary sphenoid and petrous apex esthesioneuroblastoma: case report," British Journal of Neurosurgery, vol. 12, no. 3, pp. 264-266, 1998.

[14] S. C. Sharma, C. E. E. Reddy, S. S. Srinivasan, A. Rawal, and D. P. Singh, "Isolated esthesioneuroblastoma of sphenoid sinus," American Journal of Otolaryngology, vol. 23, no. 5, pp. 287289, 2002.

[15] H. Feifel, D. Riediger, and H. V. Gartner, "Esthesioneuroblastoma. A case report," International Journal of Oral and Maxillofacial Surgery, vol. 21, no. 5, pp. 292-294, 1992. 
[16] A. Lee, D. P. Goldstein, J. Irish, F. Gentili, and B. PerezOrdonez, "Noncontiguous bilateral esthesioneuroblastoma: a case report," Skull Base, vol. 17, no. 6, pp. 405-407, 2007.

[17] S. K. Aggarwal, R. Kumar, A. Shrivastav et al., "Esthesioneuroblastoma presenting with proptosis and bilateral neck metastasis: an unusual presentation," Journal of Pediatric Neurosciences, vol. 6, no. 1, pp. 78-81, 2011.

[18] E. L. Berman, A. Chu, J. D. Wirtschafter et al., "Esthesioneuroblastoma presenting as sudden unilateral blindness: histopathologic confirmation of optic nerve demyelination," Journal of Clinical Neuro-Ophthalmology, vol. 12, no. 1, pp. 3136, 1992.

[19] S. M. García-Santana, J. A. Rodríguez, L. Serrano, and T. R. Hedges, "Esthesioneuroblastoma presenting with complete external ophthalmoplegia," Seminars in Ophthalmology, vol. 24, no. 6, pp. 245-246, 2009.

[20] A. G. Lee and R. A. Tang, "Third nerve palsy as the presenting manifestation of esthesioneuroblastoma," Journal of NeuroOphthalmology, vol. 20, no. 1, pp. 20-21, 2000.

[21] M. Hurtado-Sarriô, J. R. Artacho-Tejederas, F. Riblôn-Bornao, and C. Guillén-Fernândez, "Esthesioneuroblastoma presenting with epiphora in a young child," Archives of Ophthalmology, vol. 115, no. 10, pp. 1330-1331, 1997.

[22] J. P. Griffith, "Esthesioneuroblastoma: an unusual cause of frontal lobe dysfunction," The West Virginia Medical Journal, vol. 91, no. 4, pp. 142-143, 1995.

[23] S. Dascalu, B. Chayen, B. Kaplan, and L. Harel, "Olfactory neuroblastoma as acute postpartum depression," Journal of the American Board of Family Practice, vol. 11, no. 5, pp. 414-416, 1998.

[24] V. A. Resto, D. W. Eisele, Forastiere et al., "Esthesioneuroblastoma: the Johns Hopkins experience," Head \& Neck, vol. 22, no. 6 , pp. 550-558, 2000.

[25] F. Mattavelli, N. Pizzi, E. Pennacchioli et al., "Esthesioneuroblastoma metastatic to the trachea," Acta Otorhinolaryngologica Italica, vol. 29, no. 3, pp. 164-168, 2009.

[26] P. M. Arnold, A. Habib, K. Newell, and K. K. Anderson, "Esthesioneuroblastoma metastatic to the thoracic intradural and extradural space," Spine Journal, vol. 9, no. 5, pp. e1-e5, 2009.

[27] L. C. Pelosof and D. E. Gerber, "Paraneoplastic syndromes: an approach to diagnosis and treatment," Mayo Clinic Proceedings, vol. 85, no. 9, pp. 838-854, 2010.

[28] M. J. Cullen, D. A. Cusack, S. O’Briain, J. B. Devlin, A. Kehely, and T. A. Lyons, "Neurosecretion of arginine vasopressin by an olfactory neuroblastoma causing reversible syndrome of antidiuresis," The American Journal of Medicine, vol. 81, no. 5, pp. 911-916, 1986.

[29] W. Singh, C. Ramage, P. Best, and B. Angus, "Nasal neuroblastoma secreting vasopressin. A case report," Cancer, vol. 45, no. 5, pp. 961-966, 1980.

[30] H. Maeda, K. Tsuruya, H. Yotsueda et al., "A case report of syndrome of inappropriate secretion of antidiuretic hormone with marked edema due to administration of hypertonic saline," Therapeutic Apheresis and Dialysis, vol. 11, no. 4, pp. 309-313, 2007.

[31] Y. L. Plasencia, M. B. Cortés, D. M. Arencibia et al., "Esthesioneuroblastoma recurrence presenting as a syndrome of inappropriate antidiuretic hormone secretion," Head and Neck, vol. 28, no. 12, pp. 1142-1146, 2006.

[32] K. Miura, H. Mineta, N. Yokota, and Y. Tsutsui, "Olfactory neuroblastoma with epithelial and endocrine differentiation transformed into ganglioneuroma after chemoradiotherapy," Pathology International, vol. 51, no. 12, pp. 942-947, 2001.

[33] P. Bernard, D. Vitrey, C. Boursier et al., "Olfactory esthesioneuroma manifesting as Schwartz-Bartter syndrome," Revue de Médecine Interne, vol. 21, no. 3, pp. 278-281, 2000.

[34] B. K. Kleinschmidt-DeMasters, S. M. Pflaumer, T. D. Mulgrew, and K. O. Lillehei, "Sinonasal teratocarcinosarcoma ("mixed olfactory neuroblastoma-craniopharyngioma”) presenting with syndrome of inappropriate secretion of antidiuretic hormone," Clinical Neuropathology, vol. 19, no. 2, pp. 63-69, 2000.

[35] M. Al Ahwal, N. Jha, J. M. Nabholtz, J. Hugh, I. Birchall, and G. K. Nguyen, "Olfactory neuroblastoma: report of a case associated with inappropriate antidiuretic hormone secretion," Journal of Otolaryngology, vol. 23, no. 6, pp. 437439, 1994

[36] T. L. Pope, J. L. Morris, W. S. Cail, and D. Elkon, "Esthesioneuroblastoma presenting as an intracranial mass," Southern Medical Journal, vol. 73, no. 5, pp. 643-645, 1980.

[37] S. R. M. Freeman, S. Mitra, T. H. Malik, P. Flanagan, and P. Selby, "Expression of somatostasin receptors in arginine vasopressin hormone-secreting olfactory neuroblastomareport of two cases," Rhinology, vol. 43, no. 1, pp. 61-65, 2005.

[38] J. R. Srigley, V. S. Dayal, and R. T. Gregor, "Hyponatremia secondary to olfactory neuroblastoma," Archives of Otolaryngology, vol. 109, no. 8, pp. 559-562, 1983.

[39] J. Osterman, A. Calhoun, and M. Dunham, "Chronic syndrome of inappropriate antidiuretic hormone secretion and hypertension in a patient with olfactory neuroblastoma. Evidence of ectopic production of arginine vasopressin by the tumor," Archives of Internal Medicine, vol. 146, no. 9, pp. 1731$1735,1986$.

[40] V. Nabili, M. St John, P. Cohan et al., "Radiology quiz case 1. Catecholamine-secreting olfactory neuroblastoma (OFN)," Archives of Otolaryngology, vol. 132, no. 3, pp. 344-345, 2006.

[41] S. Galioto, A. Di Petrillo, M. Pastori et al., "Metastatic esthesioneuroblastoma secreting adrenocorticotropic hormone in pediatric patients," Journal of Craniofacial Surgery, vol. 22, no. 5, pp. 1924-1929, 2011.

[42] D. M. Mintzer, S. Zheng, M. Nagamine, J. Newman, and M. Benito, "Esthesioneuroblastoma (olfactory neuroblastoma) with ectopic ACTH syndrome: a multidisciplinary case presentation from the Joan Karnell Cancer Center of Pennsylvania Hospital," Oncologist, vol. 15, no. 1, pp. 51-58, 2010.

[43] L. Josephs, L. Jones, L. Marenette, and P. McKeever, "Cushing's syndrome: an unusual presentation of olfactory neuroblastoma," Skull Base, vol. 18, no. 1, pp. 73-76, 2008.

[44] B. K. Koo, J. H. An, K. H. Jeon et al., "Two cases of ectopic adrenocorticotropic hormone syndrome with olfactory neuroblastoma and literature review," Endocrine Journal, vol. 55, no. 3, pp. 469-475, 2008.

[45] K. Kanno, Y. Morokuma, T. Tateno et al., "Olfactory neuroblastoma causing ectopic ACTH syndrome," Endocrine Journal, vol. 52, no. 6, pp. 675-681, 2005.

[46] J. Yu, C. A. Koch, A. Patsalides et al., "Ectopic cushing's syndrome caused by an esthesioneuroblastoma," Endocrine Practice, vol. 10, no. 2, pp. 119-124, 2004.

[47] M. A. Arnesen, B. W. Scheithauer, and S. Freeman, "Cushing's syndrome secondary to olfactory neuroblastoma," Ultrastructural Pathology, vol. 18, no. 1-2, pp. 61-68, 1994.

[48] M. Reznik, J. Melon, and M. Lambricht, "Neuroendocrine tumor of the nasal cavity (esthesioneuroblastoma). Report on 
one case with paraneoplastic Cushing-like syndrome," Annales de Pathologie, vol. 7, no. 2, pp. 137-142, 1987.

[49] S. Sharma, W. Lasheen, and D. Walsh, "Paraneoplastic refractory hypercalcemia due to advanced metastatic esthesioneuroblastoma," Rhinology, vol. 46, no. 2, pp. 153-155, 2008.

[50] S. Ejaz, R. Vassilopoulou-Sellin, N. L. Busaidy et al., "Cushing syndrome secondary to ectopic adrenocorticotropic hormone secretion: the University of Texas MD Anderson Cancer Center Experience," Cancer, vol. 117, no. 19, pp. 4381-4389, 2011.

[51] R. M. Reynolds, P. L. Padfield, and J. R. Seckl, "Disorders of sodium balance," British Medical Journal, vol. 332, no. 7543, pp. 702-705, 2006.

[52] H. J. Wilson and L. E. Shutt, "Syndrome of inappropriate $\mathrm{ADH}$ secretion in a woman with preeclampsia," International Journal of Obstetric Anesthesia, vol. 16, no. 4, pp. 360-362, 2007. 


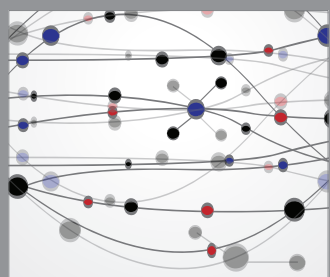

The Scientific World Journal
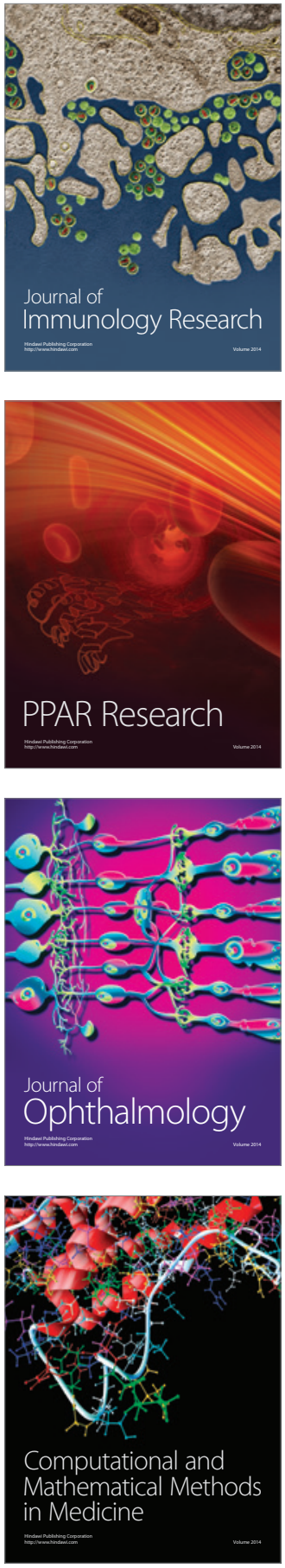

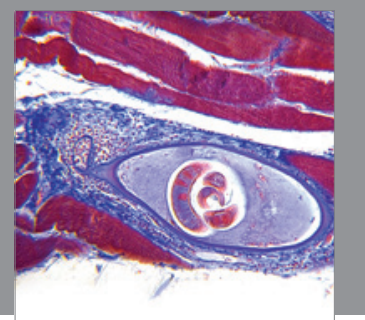

Gastroenterology

Research and Practice
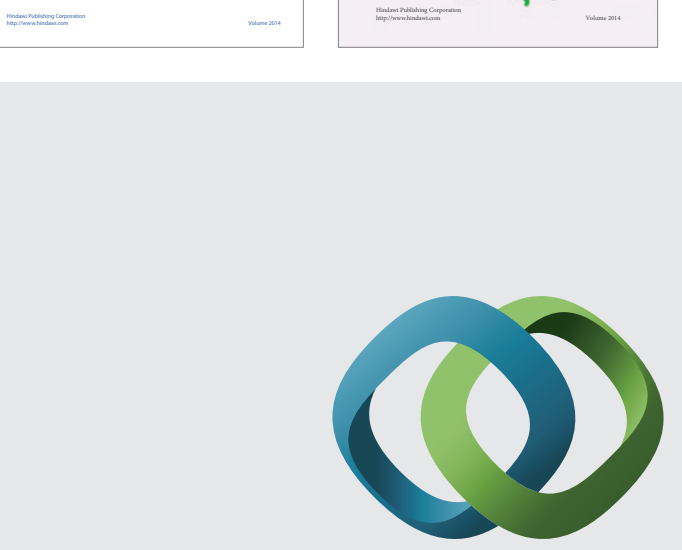

\section{Hindawi}

Submit your manuscripts at

http://www.hindawi.com
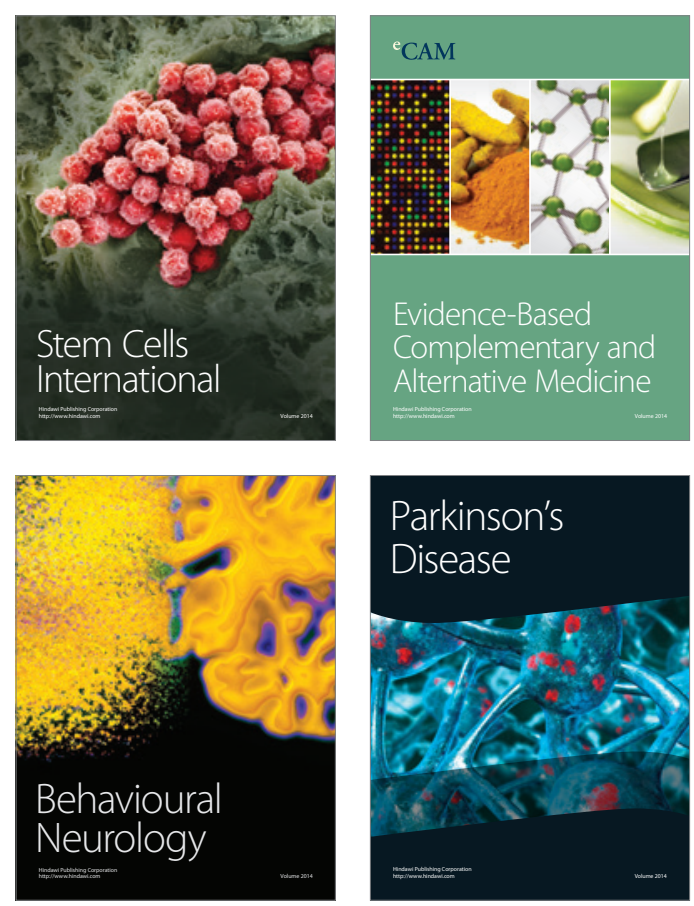

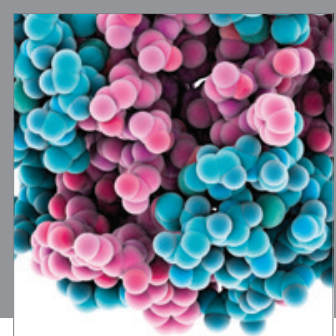

Journal of
Diabetes Research

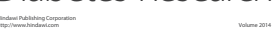

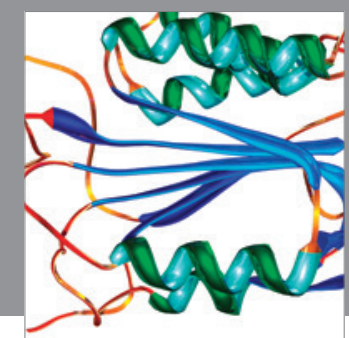

Disease Markers
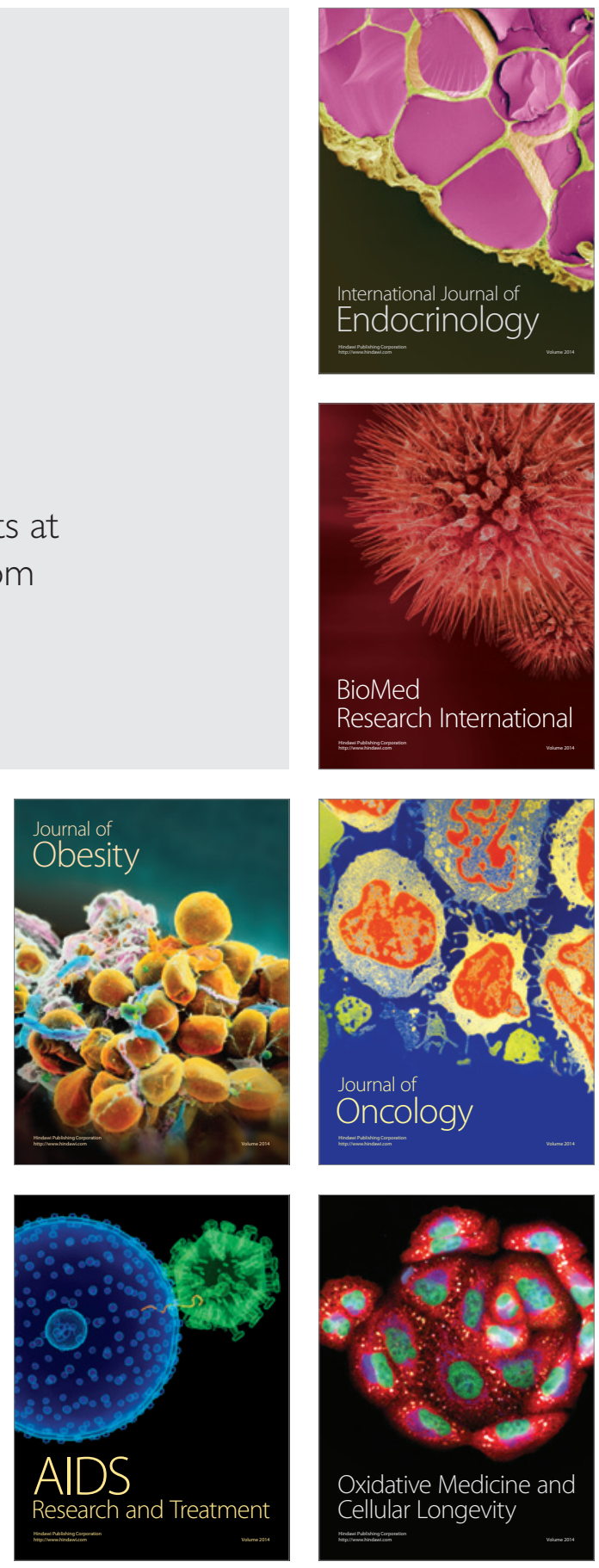